\title{
The Language Issue in South Africa: The Way Forward?
}

\section{Dr Walter W. Mpofu Chimbga}

Second PhD Candidate at the University of South Africa walterchimbga@yahoo.com

\author{
Prof Corinne Meier \\ Department of Early Childhood Education, College of Education, University of South Africa \\ meierc@unisa.ac.za
}

\section{Doi:10.5901/mjss.2014.v5n20p1424}

\section{Abstract}

South Africa attained independence twenty years ago in 1994 but the effects of the previous apartheid government still has remnants that continue to affect the status quo of many aspects of life. In terms of language, the apartheid government policies elevated English and Afrikaans languages to be the languages of government, industry, higher education, business and for all formal documentation. English has remained the de facto language of almost all spheres of life in South Africa and its linguistic domination appears as if it will continue for a very long unforeseeable future. Whilst the county's constitution is so elaborate in terms of according parity to the eleven chosen official languages, the parity ends on paper, as English has remained the language of communication in almost all formal communications. There seems to be petite political effort from the present government to ensure parity of all languages in order for all the formerly disadvantaged languages to become at par with English in terms of use as languages of higher education, business, industry commerce and television. Academically, South Africa has continuously produced unsatisfactory results at matric level, which can be summarily attributed to the use of English as the main learning language yet many do not master it. This paper sought to check how far South Africa has gone in ensuring language parity through a review of literature. The examined literature revealed that English is still dominating all the other languages and has remained the de facto language of all formal communications even though the country's constitution explicitly emphasises that all languages are equal. As it is apparent that English is a language that seems to guarantee individuals with an easy path into the global, industrial, commercial and business spheres, ways of ensuring that students master it as early as possible through improved teaching methods is the way to go as the other languages are still very limited to be used as academic languages.

Keywords: mother language/tongue, indigenous language, language policy, constitution, official language, diversity, ethnicity

\section{Introduction}

South Africa suffered immensely due to political policies in the past that endeavoured to among other things, use language as a weapon to divide the country into tribal fiefdoms for pejorative agendas of the apartheid government, which sort to disfranchise the populace and further the interests of the ruling elite class. The previous policies contributed to the upliftment and development of English and Afrikaans as the only official national languages in South Africa (Ngcobo (2007). Ngcobo (2007) further states that, "As a result of such policies (apartheid government policies), all other African languages in this country were marginalized. To address the issue of previous imbalance, the government declared 11 languages as the official languages of the country to be used at all levels." In a democratic new South Africa and twenty years after attainment of that democracy, some feel that it is time to restore the dignity and identity of many South Africans through mother language learning. Contrary to that assertation, this paper seeks to argue that, based on the current language status quo in South Africa, it is more practical to cement the acquisition of English as early as possible in the cognitive development stages of learners. Since six out of seven subjects at high school are offered exclusively in English, it is felt to be more practical to indeed ensure that learners master English language as early as possible rather than try to grasp with both six subjects' content matter and also try to master English later on in high school. It is only a very strong and intense political will that can make conditions suitable for proper mother language education to become a reality in South Africa through radical political pressure and massive human and material resources injections.

Howie, Staden, Tshele, Dowse and Zimmerman (2012) state that South African learners tested during an international comparative evaluation of reading literacy through the Progress in International Reading Literacy Study 
(PIRLS) (2011) in all African languages achieved very low scores with none reaching the International Centre point despite most writing in their home language. The fact that learners, particularly those tested in African languages, in international performance standards examinations achieved well below the International Centre point despite writing easier assessments than those used by the rest of the other countries taking part in the assessments should be a cause of concern for those who believe teaching learners in their mother language boosts academic performance. South African learners had to write prePIRLS assessment tests for the PIRLS (2011) which were easier as compared to those used by their counterparts internationally due to concessions based on earlier poor performance in the 2006 PIRLS, but they still performed badly (Howie et al 2011).

Motha and Ramadiro (2005) state that, "The policy (in South Africa) requires that children be taught through their mother tongue in the first three years of schooling and then be taught through the medium of English or Afrikaans from grades 4 to 12. The idea is that schools should, over time, increase the number of years spent in instruction through the mother tongue." Arguments to support this school of thought are based on the postulations that children understand better in their mother languages hence the need to enforce the language policy compelling all foundation phase learners to receive education in their mother languages. In that regard Alexander (2003:13) cites the following Unesco 1953 passage, "It is axiomatic that the best medium for teaching a child is his (sic) mother tongue. Psychologically, it is the system of meaningful signs that in his mind works automatically for expression and understanding. Sociologically, it is a means of identification among the members of the community to which he belongs. Educationally, he learns more quickly through it than through an unfamiliar linguistic medium. But it is not always possible to use the mother tongue in school and, even when possible, some factors may impede or condition its use."

This line of thought has indeed been regurgitated in many countries that have gone on to enforce similar policies of ensuring that children are not exposed to foreign language learning until specified times in their lifetime. This paper argues that contrary to the view that mother language learning at early cognitive years can produce better academic results, the opposite seems to be more practical considering the current status quo of the language issue in South Africa. Foley (2010) rightly contends that the question of mother-tongue education in South Africa remains a vexed one. Foley (2010) further notes that in terms of mother tongue education in South Africa, there are some very real difficulties involved in the implementation of this ideal.

\section{Aim of the Study}

The fact that learners, particularly those tested in African languages, in international performance standards examinations achieved well below the International Centre point despite writing easier assessments than those used by the rest of the other countries taking part in the assessments is indeed a cause of concern. The aim of this paper was to attend to the question whether the provision of education in mother languages has a positive effect on learner performance versus the provision of learning in a foreign language that is English, which is widely used all over the country and globally.

\section{Methodology}

The aim of the paper was explored through a systematic literature review by utilizing a fusion of contextual as well as conceptual review methods. A thoughtful and informed review of relevant literature puts the researcher in a framework of apposite studies where information from an exciting body of completed and recorded work can be considered in light of the researcher's own concerns and situation (Fraenkel \& Wallen 2010:67). As educational practitioners, the researchers found it necessary to check the status of the contentious issue of language in South Africa in an effort to put forward recommendations that might assist the debate whether the provision of education in mother languages has a positive effect on learner performance versus the provision of learning in a foreign language, that is, English.

Extensive internet use through the World Wide Web and reverting to search engines such as Google, Google Scholar and Yahoo was also employed. The advantages of using an internet search includes currency, access to a wide variety of material and immediacy (open 24 hours a day), but the disadvantages of disorganization, time consuming, uncertain reliability and lack of credibility (Fraenkel \& Wallen 2010:68) limited the use of the internet in searching for literature on the language issue in South Africa.

\section{The Current Language Situation in South Africa}

On paper, that is, in the South African constitution, it is stated that there are 11 official languages in the Republic of South Africa, namely Sepedi, Sesotho, Setswana, siSwati, Tshivenda, Xitsonga, Afrikaans, English, isiNdebele, isiXhosa and 
isizulu. While the constitution rightfully declares that there is need to recognise the historically diminished use and status of the indigenous languages of the populace and the need for the state to take practical and positive measures to elevate the status and advance the use of these languages, the reality is that the 11 official languages are not treated equally. Some languages seem to be given more preference over the others. The Constitution of the Republic of South Africa No. 108 of 1996 (1996) state that the Pan South African Language Board (PANSALB) established by national legislation must promote and create conditions for the development and use of all official languages. Despite the legislation's position, Malatjie (2014) complains about the state of affairs when she notes that, "It's often said that South Africa is a land of equal opportunities, but I beg to differ. Yes, we do have 11 official languages, but the treatment these languages get is not equal. Nguni, Sepedi, Sesotho and Setswana languages get a lot more publicity compared to the Xitsonga and Tshivenda languages." Malatjie (2014) goes on to protest that the preferred languages are used to name national sporting teams and campaigns whilst at the same time they get preferential treatment on national television.

Alexander (2003:16) points out that post-apartheid South Africa has established an impressive array of language planning agencies and other language policy implementation institutions such as the PANSALB which has a provincial language body in each of the nine provinces and each of the 11 official languages has a lexicographic unit, usually located in one or more universities. Alexander (2003:16) follows the above stated observation by noting that such initiatives have been merely on paper as there are many practical problems as well as lack of political will and strategic clarity in respect of the evolving language dispensation. The lack of political will mentioned here has led many scholars, analysts, disgruntled members of the populace and academics to come up with competing views in terms of the language issue as there is no clear course of action to ensure that what is on paper as legislation is holistically put into practice.

In an effort to understand the dynamics of the issue of language in South Africa, a consideration was made to go over various legislations that deal directly with language matters and one of the Acts encountered is Act No. 12 of 2012: Use of Official Languages Act, (2012). What quickly catches one's eye is the inscription in red perched right at the top of the cover page, which reads, "Please note that most Acts are published in English and another South African official language. Currently we only have capacity to publish the English versions. This means that this document will only contain even numbered pages as the other language is printed on uneven numbered pages." This caption quickly recapitulated the hypothesis that, English undoubtedly commands more privileges than any other South African "official languages'. The word official languages is in quotation marks here because some languages are simply referred to as official languages on paper and it ends there without featuring anywhere in society and even in the school arena. Whilst the Use of Official Languages Act, 2012 was designed so that it contains both English and an alternative language, it is so unfortunate that the very policy on language cannot be produced in all the recognised languages except for the only esteemed one, that is, English.

According to Statistics South Africa (2012:18), the white populace constitutes only $7.9 \%$ of the total population whilst the indigenous South Africans make up 79.2\% (almost 80\%) of the total population. In light of these population figures, it would make more sense to print important documents such as the laws of the country in languages of the masses but the language of the minority is preferred. The argument here is that, it is apparent that less than $8 \%$ of the South African population has English as a mother language yet the language is still widely accepted as the 'official' language in terms of government communications both verbally in the legislature and in written form for important documents such as the laws of the country. The Gauteng Language Policy Framework (GLPF) (2005) mentions linguistic justice when one of its objectives states that it aims to promote the equitable use of the 11 official languages of the province in order to realise social, cultural and linguistic justice. Linguistic justice will therefore only be realised if all the 11 official languages are treated equally without preference being given to one or two languages.

The current South African curriculum requires learners at high school to do six out of seven subjects in English (and in some cases Afrikaans) only and just one in a learners' mother language or implied mother language. Many learners are forced to learn in an implied indigenous mother language as only four indigenous languages, that is, Xhosa, IsiZulu, Sepedi and Xitsonga are the ones offered in most schools as it is presumed that all the other vernacular languages' speakers should make a choice of a language closer to theirs. This state of affairs makes other members of society uncomfortable who like Malatjie (2014) mentioned earlier on, complain about the state of affairs which seem to give preference to some languages over others. Malatjie's (2014) argument is very genuine, as a language like Tshivenda is in no way related to any of the languages that are widely offered in public schools as the accepted home languages. The idea of offering only four African languages in schools is based on a simplistic view that African languages in South Africa must belong either to Sotho or to Nguni language dialects. The simplistic idea negates the tenets of the country's constitution that respects each official language on its own and esteems it as a unique language separately that has to be accorded full support to elevate its status and ultimately further the interest of each unique tribe into the future without being an appendage of another dialect. 
The University of South Africa (Unisa) language policy (2006) quotes Nelson Mandela in its forward when he stated that, "Today, when we have to deal with a new reality of a university most of whose students are now black and predominantly rural or semi-urban, great challenges emerge. Not least is the vexing question of a language policy that should honour the preferences of the students themselves." In light of the point put across by Mr Mandela, it is clear from the earlier given statistics that the indigenous people of the country make up $79.2 \%$ of the South African population, which rightfully translates to huge numbers of students from that population group. Instead of the language scales to tip more in favour of the majority, the minority's language is still the official language of all institutes of higher learning. Unisa's language Policy (2006) correctly states that, English has become the lingua franca, particularly of the formal economy and of the academic field, even though it is a language, which is a mother tongue of the minority. English has indeed become more powerful in the whole world and has become the de facto language of globalization and since South Africa is not an island, it is also affected by the events taking place globally. Unisa language policy (2006) further notes that, although most educational institutions proclaim policies which recognise the multilingual and multicultural make-up of the South African society, in essence very little is done to implement tuition and support that accord with a 'rainbow' nation vision. The Unisa language policy (2006) also notes that this happens despite government initiatives such as a Ministerial Committee to advise on the development of indigenous African languages as mediums of instruction in Higher Education.

Yu (2012) states that the enrolment trend for studying South African official languages as a major at undergraduate level by three groups: English, Afrikaans and all indigenous languages illustrates a substantial fall in enrolment for indigenous languages. The enrolment trend shows that the combined enrolment for all nine indigenous languages amounts to a very small numerical figure as in 2009, it reduced to less than that of one single language subject: Afrikaans. Using the graduation/enrolment ratio as an indication for throughput rate, statistics shows that the throughput rate for all South African official languages has worsened over the years, with fewer students studying languages, and even fewer graduating majoring in indigenous languages (Yu 2012). In the same vein, Maake (2014) states that during his university years, those who took a major in an African language were the laughing stock of their peers. This scenario can be a pointer in terms of how many young people might feel about pursuing a career specialising in indigenous languages didactics. It can be argued that a thorough and nationwide extensive research on what the people exactly want is indeed required to test whether mother language education is undeniably the wish of the majority or it is just a wish for some people who simply want to further certain agendas.

The GLPF (2005) alludes to the fact that, the following are the sections of the Constitution of the Republic of South Africa Act No. 108 of 1996 (1996) that were taken into consideration in its drafting:

- Section 6(1) declares that the official languages of South Africa are Sepedi, Sesotho, Setswana, siSwati, Tshivenda, Xitsonga, Afrikaans, English, isiNdebele, isiXhosa and isiZulu.

- Section 6(2) recognises the historically diminished use and status of the indigenous languages of South Africa, and compels the state to take practical steps and design mechanisms to elevate the status and advance the use of these languages.

- Section 6(4) obliges national and provincial governments to regulate and monitor their use of official languages to ensure parity of esteem and equitable treatment.

- Section 6(5) provides for the establishment of PanSALB to promote and develop the use of all the official languages, as well as Khoi, Nama, San and Sign Languages, and to promote respect for all languages commonly used in communities in South Africa.

- Section 9(3) protects citizens against unfair discrimination on the grounds of language.

- Section 29(2) states that everyone has the right to receive the education in the official language or languages of their choice in public institutions where that education is reasonably practicable. In order to ensure the effective access to, and implementation of, this right, all reasonable educational alternatives must be considered, taking into account equity, practicability and redress.

- Sections (30) and 31(1) uphold the rights of citizens to use the language of their choice.

These plausible constitutional rights however remain a wish list as basically no effort is made to ensure that they are implemented. This is because only certain languages are promoted at the expense of the others. Public schools in Gauteng offer mainly only four prescribed African languages as opposed to the above stated scenario of according each one of the 11 official languages parity. Motha and Ramadiro (2005:13) state that, "Many South African public schools are not delivering on the language policy in education of the country. The policy requires that children be taught through their mother tongue in the first three years of schooling and then be taught through the medium of English or Afrikaans from grades 4 to 12." There are no mechanisms in place to ensure that schools do surveys at the beginning of every academic 
year to check the actual mother languages of learners but the situation is simply for learners to choose a language amongst the prescribed 'big' four. This scenario is reminiscent to the apartheid system which discriminated other languages and forced learners to be taught in Afrikaans leading to the famous 1976 Soweto uprising and will be outlined in the next paragraphs.

The apartheid government separated indigenous South Africans according to language and resettled them separately in 'homelands' (Homeland or Bantustans were areas that were reserved for indigenous Africans by the then apartheid government according to their ethnic grouping in terms of language). The 'Bantustan' policy (of the apartheid government) deceivingly sought to assign indigenous Africans to a homeland according to their ethnic identity. The 'homelands' were sardonically named chiefly according to the languages of the indigenous Africans and had names such as KwaNdebele, KwaZulu, Venda and Bophuthatswana which all incorporate a language name. What is now happening is that, institutes of higher learning located in areas of the former 'homelands' are literally forming language policies that are in line with fostering the colonial government's intentions as they are now exclusively nurturing the former homeland language alongside the traditional university languages of learning, that is, English and Afrikaans. The language policy of the University of KwaZulu-Natal (2006) explicitly states that, "The policy for the University makes clear the development of an awareness of multilingualism through an acknowledgement of all the official languages of KwaZulu-Natal, namely isiZulu, English and Afrikaans. The policy for the University makes clear the need to achieve for isiZulu the institutional and academic status of English and provision of facilities to enable the use of isizulu as a language of learning, instruction and administration." In the same vein, the University of Western Cape (2003) also, states that, "Regarding the languages used in the setting of tasks, assignments, tests and examinations, English, Afrikaans and Xhosa should be used where it is practical to do so."

Whilst there is totally nothing wrong with these universities' ethos, it appears as if they are furthering the interests of certain population groups as opposed to embracing the notion of South Africa being a rainbow nation. The University of KwaZulu-Natal Language Policy (2006) states that, "The University equally recognises the importance of isiZulu as a custodian of culture, heritage, and tradition and as a means of communication. Isizulu is one of the official South African indigenous languages named in the Constitution, whose 'use and status' have been 'historically diminished'. The University, following the Constitution, is bound to 'take practical and positive measures to elevate the status and advance of the use of isizulu'." These stated aims of the University of KwaZulu-Natal are so clear in terms of the university's objectives of solely advancing isizulu with total disregard of the other African languages whose 'use and status' have also been equally 'historically diminished'. The point that states that the University recognises the importance of IsiZulu as a custodian of culture, heritage, tradition and as a means of communication will be appreciated by an Isizulu student or staff member whilst at the same time can be easily misunderstood by non-Isizulu students and staff members to mean that their languages are inferior.

There can be arguments to support the routes taken by institutes of higher learning, which may be very valid to some, but what the language policies clearly depict is that the country is still far from efforts to bring about parity for all the official languages of South Africa. The fear is that, rather than being all embracing institutes and catering for the needs of everyone, there seems to be very strong signs of higher institutes of learning being ethnic to cater for particular formerly disadvantaged groups' interests at the expense of the other ethnic groups. Rather than focusing on single groups, it is in all fairness more reasonable for higher institutes of learning to be impartial and be comprehensive by focusing on ways to achieve language parity universally in line with the constitutional rights of all official and perceived unofficial languages. Bastardas (2002) comments that there is a widely-held belief in certain geo-cultural areas that generalised social bilingualism usually or even inevitably leads to a process of language shift, that is, the 'weaker' languages gradually lose functions whereas the 'stronger' languages gains functions, and the process ends with the abandonment of other groups' own code, that is, language death. Bastardas (2002) therefore suggests that correlatively to polyglottization, subsidiarity and exclusive functions, all levels of political authorities should supervise the prevention of a trend that could well take place, that is, an advantageous streak by bigger languages. It can be a worthwhile and interesting endeavour to carry out research at higher institutes of learning with tapered language policies and find out how other academics and students with languages not considered as 'official' institutional languages feel about such status quos.

Unisa's language policy (2006) has many realistic standpoints in relation to language issues in South Africa and does not hide the reality that "There is no doubt that the place of English as the primary language of instruction is assured." The policy also makes it clear that, "It is unrealistic to expect that in the foreseeable future a major shift will occur towards tuition through the medium of African languages. Moreover, given the demands of the local and global economy, a policy to teach everything through the medium of African languages is likely to be detrimental to the interests of the students." Unlike the majority of other language policy documents' tenets, the Unisa's language policy (2006) makes the following rational facts: 
- The ideal of multilingualism is yet to be achieved in South African universities.

- Most students are studying through the medium of English even though this may be their second or third language.

- Language development and support must be generic and contextualised to the discourses of different discipline and subject areas.

- Languages have complex implications in terms of identity and social integration, both globally and locally, and thus are of strategic importance. They are not only tools of communication, but also, and mainly, systems of perception and thought, mirrors of cultural identity and vectors of its fundamental values. They are an essential constituent of the self-consciousness and identity of individuals and societies, and are the basis for the creation, processing and transmission of knowledge. The capacity of peoples to live in and modify their environment, interact and socialize is heavily dependent on and marked by their language faculty. Thus, marginalization or integration, exclusion or empowerment, poverty or development, are to a certain extent determined by linguistic choices and strategies.

- There is evidence to indicate that a more enlightened approach to language issues would ensure better student throughput, more opportunities for meaningful communication between staff and students and contribute to the notion that Unisa offers a conducive learning environment. If, for example, in the long term, a policy of additive bilingualism were to be implemented whereby only the largest African language (namely Zulu) were added as a medium of instruction, the percentage of Unisa students able to access learning in their primary language increases dramatically to $67 \%$. However, it is unrealistic to expect that in the foreseeable future a major shift will occur towards tuition through the medium of African languages. Moreover, given the demands of the local and global economy a policy to teach everything through the medium of African languages is likely to be detrimental to the interests of the students. Such a position may even be the cause of hostility.

- The diverse nature of tertiary students and the complex matrix of competencies and needs require that all interventions are based on sound empirical evidence. Language development programmes that are not tailored to the specificities of their target audiences are unlikely to produce quantifiable, qualitative improvements.

- While Unisa does not have the capacity to address either deficiency in its totality, it believes that it would be highly advantageous to begin tackling the problem during schooling and before students enrol for tertiary study. Consequently, this proposal suggests that in-service teachers and/or mentors/tutors are identified in each of South Africa's nine provinces and that these people are empowered in a train-the-trainer learning pyramid to build language capacity within the framework of multilingual approaches. The proposal also suggests that Unisa and its partners liaise closely with the National Ministry of Education and with provincial education departments to co-operatively produce and distribute low-cost, multilingual language development and support programmes on a massive scale. This twin approach targets increasing human capacity and the urgent need for all schools to be provided with an array of learning resources.

In summary of the above outlined standpoints, it is clear that language parity in South Africa still remains a vision as English has stood out as a dominant language over all the other languages and more effort is greatly required by those in authority to bring all the official languages at par. The University of the Witwatersrand Language Policy (2003) notes that Johannesburg is a city, which is so linguistically diverse, which in turn complicates decisions about language policy. It further states that at the University of the Witwatersrand, staff and students speak 76 different home languages, which makes it difficult for the institution to choose which language/s to develop and use, as no choice will satisfy the needs of all its staff and students. Both the University of South Africa and the University of the Witwatersrand operate as international universities and the dilemma to choose official languages indeed become difficult, as more than seventy languages exist at each of these universities and their language policies sharply differ with those of other universities.

The deductions made from studies of various government statutes, institutional language policy documents and provincial policy documents simply point to the fact that, it is clear that the national policy on language ends on paper as government departments, institutions, schools and provinces are granted broad rights to decide their individual language policies. The scenario has left other languages to be pushed away into no man's land as the situation clearly show that certain languages are preferred in contravention of the tenets of the South African constitution. The GLPF (2005) assert that, "The Language-in-Education Policy states that all learners should be offered the opportunity to learn at least one indigenous language, all language learning areas should receive equitable time and resources..." However, reality unfortunately shows that, all learners are to be offered the opportunity to learn at least one prescribed indigenous 
language and only the prescribed language learning areas should receive equitable time and resources as other languages are not available to learners to choose them.

\section{The State of Education as a Whole in South Africa}

Meier (2011) categorically states that, the education system in South Africa has failed to produce competent learners. Meier (2010) goes on to note that according to the Department of Education (2008), learners are not able to read, write and count at expected levels, and they are unable to execute tasks that demonstrate key skills associated with literacy and numeracy. Higher education institutions feel the effect of a failed system seriously as many of the country's first-year students cannot read, write and comprehend to a satisfactory extent (Meier 2010). According to Meier (2010), the incompetence of South African learners was demonstrated in South Africa's Grade 8 learners' performance in Mathematics and Science in the Trends in International Mathematics and Science Study (TIMSS) in 1995 that was significantly lower than that of learners in all the other participating countries in the study. The study also highlighted the relation between the inability to read and write and poor performance in Mathematics and Science. Learners showed not only a lack of understanding of mathematical and science questions but also an inability to communicate their answers verbally and in writing (Howie in Meier 2010). It is clear that the inability to communicate answers verbally and in writing specifically refers to English language as both mathematics and Science are taught mainly in English in South Africa. Meier (2010) goes on to note that thirteen years later after the 1995 TIMSS study, that is, in 2008, the Department of Education reported that for the Annual National Assessment (ANA) of Grades 3 and 6 on average, out of 10 learners, eight are functioning at levels lower than $50 \%$. Parents and educationists labeled the poor performance of learners in the 2008 ANA as 'a scandal' (Mail \& Guardian in Meier 2010). Eight out of ten translates to $80 \%$ of learners failing to reach half $(50 \%)$ of expectations.

A mark of 30\% of the total mark in tests, school based assessment tasks and all school major examinations constitute a pass in South Africa (Department of Basic Education 2012). The South African National Policy pertaining to the programme and promotion requirements of the National Curriculum Statement Grade R-12 (2012:25) states that the elementary achievement level percentage band ranges between 30 and 39\%. These standards have over the years drawn the ire of many people who feel that this borders on making the education system of South Africa ineffective, as $30 \%$ is way below the $50 \%$ half mark which in turn have serious repercussions later in life, as the rate of dropouts at university level is very significant. One prominent academic who scoffs at the $30 \%$ pass rate is in fact one of the Vice Chancellors of South Africa's 23 universities, that is, Professor Jonathan Jansen of the University of Free State. Professor Jansen (2012) writes "If I had to make the choice with my own children today, I would seriously consider not sending my child to school in South Africa, for one simple reason: I do not trust a system that makes it possible for a child to pass Grade 12 with $30 \%$ in some subjects and $40 \%$ in other subjects. I would be filled with fear when I discover that you can get $32 \%$ in mathematics and $27 \%$ in physical science and still get an official document that says you can continue to study towards a Bachelors degree at university." He (Professor Jansen 2012) goes on further to contemptuously state that, "It is extremely difficult to fail Grade 12 in South Africa today. You have to put in a special effort, miss your classes, deliberately provide wrong answers to questions, and hand in your paper early during an exam session and maybe, just maybe, you will fail." In short, Jansen is basically not amused by the low standards that are upheld in South Africa which make $30 \%$ of any total expected mark a pass since this is very poor by international standards that are upheld in many other countries that consider any mark below the half mark of $50 \%$ a fail.

In its own self-evaluation undertaking, the South African Department of Basic Education (DBE) carried out an extensive research that culminated in the production of the final report entitled The Internal Efficiency of the School System: A Report on selected aspects of access to education, grade repetition and learner performance (2013). The major highlights stated in the report are that:

- The major inefficiency observed in the system is the low quality of learning and teaching that characterizes many of the South African schools. This problem is especially severe in the early grades and manifests in a delayed and incomplete acquisition of foundational skills such as reading, writing and numeracy, which are crucial for subsequent learning.

- There are high levels of school dropouts as from around the age of 16.

- The level of performance of South African learners is still low by international standards as revealed by comparative TIMSS studies.

- The widespread failure of South African children to reach basic thresholds of literacy and numeracy has been echoed by other international tests such as the various TIMSS and PIRLS studies as well as the DBE's ANA. 
Approximately 95\% of grade 5 children in schools that took the PIRLS 2006 survey of reading achievement in one of the African languages performed below the lowest benchmark category.

- There is sufficient evidence of weak content knowledge amongst South African teachers to warrant attention.

The issues noted by the DBE above clearly outline some very serious challenges that need serious attention in order for the performance of South African learners to rise to comparable standards that are evident in many other countries. If $95 \%$ of a specific target performs below expectations especially when the competency tests are in a learner's mother language, then this is indeed something that should ring very loud alarm bells for every stakeholder in the education fraternity of the country. Whilst some people may argue that learners understand better when taught in their own mother languages, the results of the above outlined competency endeavours clearly tells something very different from such an assertion. Many studies have been conducted in South Africa whose results clearly indicate that the claim that mother language learning can yield preferable results is just a fallacy. One such study is the Progress in International Reading Literacy Study (PIRLS) (2011) conducted in learners' mother language that has earlier on been alluded to. Howie, Staden, Tshele, Dowse and Zimmerman (2012) state that PIRLS is an international comparative evaluation of reading literacy of Grade 4 learners and was conducted in 49 countries with 325000 learners in 2011. According to Howie et al (2012) PIRLS is one of the largest, most complex and influential assessments of reading literacy internationally, and in South Africa, almost 20000 learners from 433 schools in Grade 4 (341) and Grade 5 (92) participated. Howie et al (2011) further state that South Africa had also participated in PIRLS 2006, with more than 30 000 learners in more than 400 schools participating in all South Africa 11 official languages in Grades 4 and 5, representing the largest and most ambitious national contribution to an international comparative study. Howie et al (2012) state that the 2006 PIRLS results released in 2007 revealed a very low level of achievement in South Africa. At both Grades 4 and 5 , the average performance of learners was almost 200 points below the international average of 500 points at both grades (Howie et al 2012).

Howie et al (2012) point out that the low achievement results led directly to a change in the national design for PIRLS 2011. At the Grade 4 level, a decision was made to assess the learners with an easier assessment, called prePIRLS, designed by the International Study Centre with the assistance of the national centres. Processes similar to those of PIRLS were followed in the design and development of pre-PIRLS, but designed as a shorter and easier test and at a lower cognitive level than that of the actual international PIRLS 2011. This pre-PIRLS 2011 represented a new baseline measure for South Africa for Grade 4 and was administered in all 11 languages, meaning that, due to previous poor performance, easier test items were now administered to South African learners whilst the rest of the world stuck to the International standards.

Using the pre-PIRLS the following key findings emerged as summarised by Howie et al (2012):

- Grade 4 learners, particularly those tested in African languages, achieved well below the International Centre point despite writing an easier assessment. They were still performing at a low-level overal on an easier assessment than were their counterparts internationally.

- Learners tested in all African languages, despite most writing in their home language, achieved very low scores with none reaching the International Centre point. Learners tested in Sepedi and Tshivenda had average scores more than 100 points below the International Centre point of 500 points and represented the poorest performing African language groups for purposes of the pre-PIRLS 2011 study.

- Of concern is that more than half of the learners tested in Sepedi and Tshivenda could not read at a fundamental level and failed to reach even the Low International benchmark. This failure points to an inability to locate and retrieve explicitly stated detail when reading literary texts. When reading informational texts, not reaching the Low International benchmark also implies an inability to locate and reproduce two or three pieces of information from within the text, and to use subheadings, text boxes and illustrations to locate parts of the text when reading informational texts.

- Grade 5 learners tested in Afrikaans or English were still performing below the International Centre point of 500 fixed for the reading literacy of Grade 4 learners internationally, by approximately 80 points.

- Forty-three percent of learners in Grade 5 tested in Afrikaans and English were unable to reach the

Lowest International benchmark and only 4\% could reach the Advanced International benchmark, compared to 8\% internationally

The issues outlined here clearly indicate that there is generally poor performance from learners in South Africa and the argument that mother language learning produces preferable results does not hold as there are undesirable poor results produced from simple literacy tests in learners' mother languages. This clearly points to the fact that the situation will be even worse if ever such languages were to be used for more complex subjects such as sciences, accounting and 
technical subjects.

\section{The Inevitable Position of English in South Africa}

The perspective of this paper is that English will unfortunately remain the lingua franca of the academic, globalisation and business worlds for a much-unforeseen long time unless radical and comprehensive steps are taken by the political leaders in order for other alternative languages to be developed to meaningful lexicology levels. This ideology is based on conclusions made after a careful perusal of several language policies for various South African national departments, national public entities, national public enterprises and institutions. Some of the language policies consulted emphatically state the following:

- The Language policy of the University of KwaZulu-Natal (2006:1) states that, "The University will continue to use English as its primary academic language..." The policy also states, "The benefits for students becoming proficient in English, the dominant medium of academic communication and of trade and industry internationally, and the lingua franca in government and institutions in South Africa, are clear."

- The GLPF (2005:12) states that, "The language of written internal record in Gauteng Provincial Government will be English and translations into other official languages and Braille will be made available on request where practically possible."

- The University of Western Cape Language Policy (2003:1) affirms, "All students will have access to entry-level courses aimed at strengthening their English oral and aural communication skills and improving their academic literacy in English. All students will have access to support services to assist them in developing their academic literacy in English."

- The Unisa's language policy (2006) states that, "Most students are studying through the medium of English even though this may be their second or third language."

According to Maake (2014), research has proven beyond reasonable doubt that South Africans whose mother tongue is not English are confident in affirming the supremacy of English over their languages, hence a preference for English as the medium of instruction despite the right accorded by section 29(2) of the constitution to all languages. The South African constitution Section 29(2) states that everyone has the right to receive education in the languages of their choices in public educational institutions. Moya (2014) on the other hand says that, as the world commemorated International Mother Language Day, it reminded her of her colleague who says that when she has kids, they will not speak her native Setswana, but will speak only English, a dilemma that is not unique to her colleague only. Many Africans see English as a gateway into the business and global arena and prefer it over their own mother languages though some people would want the world to believe that many South Africans would prefer their own mother languages over English.

Moyo (2009) notes that, "South Africa's constitution of 11 official languages, is hailed as one of the most progressive language policies in the world, but this is only gesturising and theoretical. In practice, English and Afrikaans are the de facto languages of use in higher education, government, commerce and industry, diplomacy, and in almost all documentation. The linguistic domination continues to politicise the language question and there seems to be lack of the political will to implement appropriate policies." Moya (2014) further notes that, "The International Mothers Langauge Day reminds us that indigenous languages in South Africa are threatened by the dominance of English, and the half hearted attempts by the state to introduce the teaching of indigenous languages to all schools." Alexander (2003) correctly remarks that one of the most difficult tasks that confront progressive educationalists in South Africa is the rehabilitation of mother tongue education not only as a valid educational strategy but also as the most likely strategy to redress the educational imbalances that were inherited from the past. Ironically, Alexander (2003) comments that the only children who enjoy all the advantages of mother tongue education from the cradle to the university and beyond are in fact L1speakers of English and of Afrikaans.

Williams (2011) also notes that, "Africa is the only continent where the majority of children start school using a foreign language." Williams (2011:6) categorically states that, "If children in developing countries have little exposure to the language of instruction (be it English, French, Portuguese, etc.) outside the school, and if teaching the language of instruction is ineffective inside the school, then low quality education is inevitable. There is a considerable risk in such cases that the school experience may be a stultifying, rather than an enlightening one." It can be concluded that the most likely scenario considering the current state of affairs in South Africa is to find ways of ensuring that learners are accorded strong and rigorous foundations to master English, as the idea of using indigenous African languages for universal learning remains a vision. Foley (2006:8) notes that, "At the moment, a very small percentage of university teacher educators are able to provide quality tertiary tuition through the African students' mother tongues, and even fewer 
in the scientific subjects." Foley (2006:4) justly concludes that more needs to be done if the ideal of the African languages functioning fully as academic and scientific media of instruction in South Africa is to be actualised. Banda (2009) consequently notes that it is not surprising that in the majority of cases colonial languages have retained their official status and are the main languages of education, state functions and business in general in the whole of Africa.

The literature examined has revealed that language parity in South Africa remains an implausible idea as a lot still needs to be done since all the other official languages except for English and Afrikaans cannot be used as fully-fledged academic languages especially with the science subjects.

\section{Conclusions}

To conclude, the researchers hold the view that research is desperately needed on ways to improve the literacy of learners in English as a way of improving learners' grasp of subjects' content. It is more advantageous for students to master a language that has become the default global language that is preferred in all major spheres of life such as communications both written and verbal in parliaments, mass media, higher institutes of learning, economic and industrial arenas.

\section{References}

Alexander, N. (2003). Language Education Policy, National and sub-national Identities in South Africa. Strasbourg: Council of Europe.

Banda, F. (2009). Critical perspectives on language planning and policy in Africa: Accounting for the notion of multilingualism. Western Cape: Stellenbosch Papers in Linguistics PLUS, Vol. 38, 1-11.

Boada, A.B.I. (2002). World Language Policy in the Era of Globalization: Diversity and Intercommunication from the Perspective of 'Complexity.' Barcelona: University of Barcelona 2002.

Department of Basic Education, (2013).The Internal Efficiency of the School System: A Report on selected aspects of access to education, grade repetition and learner performance. Pretoria: Department of Basic Education.

Department of Sport, Recreation, Arts and Culture, (2012). The Gauteng Language Policy Framework.

Foley, A. (2010). Mother-tongue Education in South Africa http://www.teacherenglishtoday.org/index.php/201.

Fraenkel, J.R. \& Wallen N.E. (2010). How to design and evaluate research in education. Seventh edition. Boston: McGraw-Hill.

Howie, S., Staden, S., Tshele M., Dowse, C. \& Zimmerman, L. (2012). PIRLS 2011: South African Children's Reading Literacy Achievement Report. Pretoria: Centre for Evaluation and Assessment: University of Pretoria.

Jansen, J. (2012). Opinion Analysis Bloemfontein: University of the Free State.

Maake, N. (2014). To teach your children well, do so in their own language. Sunday Times February 16.

Malatjie, C. (2014). Equal recognition Drum March 13.

Meier, C. (2011). The Foundations for Learning Campaign: helping hand or hurdle? South African Journal of Education Vol. 31:549-560.

Motha, S. \& Ramadiro, B. (2005). Education Rights of Migrants in the Inner City of Johannesburg, South Africa Johannesburg: Khanya College.

Moyo T. (2009). Linguistic Diversity and Development: the Language Question and Social Justice in Southern Africa. The Forum on Public Policy.

Moya, F. (2014). Learn an indigenous language. The Star February 26.

Ngcobo, M.N.(2007) Language Planning, Policy and Implementation in South Africa Pretoria: University of South Africa.

South African Government, (2012). Act No. 12 of 2012: Use of Official Languages Act. Government printers: Cape Town.

South African Government, (2012). National Policy pertaining to the programme and promotion requirements of the National Curriculum Statement Grade R-12. Pretoria: Government Gazette No. 36042 of 28 December 2012.

South African Government, (1996).The Constitution of the republic of South Africa No. 108 of 1996. As adopted by the Constitutional Assembly on 8 May 1996.

Statistics South Africa, (2012). Census 2011 Statistical release - P0301.4. Pretoria: Statistics South Africa.

The University of KwaZulu-Natal, (2006). Language Policy of the University of KwaZulu-Natal. KwaZulu-Natal: The University of KwaZulu-Natal.

The University of Western Cape, (2003). The University of Western Cape Language Policy. Western Cape: The University of Western Cape.

University of South Africa, (2006). University of South Africa language policy. Pretoria: University of South Africa.

Williams, E. (2011). Language Policy, Politics and Development in Africa. United Kingdom: British Council.

$\mathrm{Yu}, \mathrm{K}$. (2012). Reclaiming indigenous languages for posterity Johannesburg: Human Sciences Research Council. 